\title{
Roles for inositol-phosphoryl ceramide synthase 1 (IPC1) in pathogenesis of C. neoformans
}

\author{
Chiara Luberto, ${ }^{1}$ Dena L. Toffaletti, ${ }^{2}$ Elizabeth A. Wills, ${ }^{2}$ Stephanie C. Tucker, ${ }^{3}$ Arturo Casadevall, ${ }^{3}$ \\ John R. Perfect, ${ }^{2}$ Yusuf A. Hannun, ${ }^{1}$ and Maurizio Del Poeta ${ }^{1,4,5,6}$ \\ ${ }^{1}$ Department of Biochemistry \& Molecular Biology, Medical University of South Carolina, Charleston, South Carolina \\ 29425, USA; ${ }^{2}$ Department of Medicine, Duke University Medical Center, Durham, North Carolina 27710, USA; \\ ${ }^{3}$ Department of Microbiology and Immunology, Albert Einstein College of Medicine, New York, New York 10461, USA; \\ ${ }^{4}$ Department of Microbiology \& Immunology, Medical University of South Carolina, Charleston, South Carolina 29425, \\ USA; ${ }^{5}$ Institute of Infectious Diseases and Public Health, University of Ancona, 60121 Ancona, Italy.
}

Cryptococcus neoformans is a leading cause of life-threatening fungal infection in immunocompromised patients. Inositol-phosphoryl ceramide synthase 1 (Ipc1) is a fungus-specific enzyme, encoded by the essential IPC1 gene, that catalyzes the formation of complex sphingolipids and may also regulate the levels of phytoceramide and diacylglycerol. Here, we investigated the functions of this essential gene by modulating its expression in C. neoformans using a galactose-inducible promoter. Down-regulation of IPC1 significantly lowers the expression of certain virulence traits such as melanin pigmentation and, remarkably, impairs pathogenicity of $C$. neoformans in an established rabbit model. Interestingly, we found that IPC1 down-regulation significantly decreases the intracellular growth of $C$. neoformans in the $\mathbf{7 7 4 . 1 6}$ murine macrophage-like cells. Finally, we studied the effect of IPC1 expression under different stress conditions and found that down-regulation of IPC1 confers a defect on in vitro growth at low $\mathrm{pH}$. Because this environment is similar to that in the phagolysosome of $\mathbf{J 7 4 . 1 6}$ macrophage-like cells, our findings indicate that down-regulation of IPC1 confers a growth defect in vivo through a $\mathrm{pH}$-dependent mechanism. In conclusion, our study is the first to define a novel and crucial function of Ipc1 in fungal pathogenesis.

[Key Words: sphingolipids; Cryptococcus neoformans; virulence]

Received October 2, 2000; revised version accepted November 29, 2000.

Cryptococcus neoformans is a common invasive opportunistic pathogen in AIDS patients, and it is the most common cause of fungal meningitis worldwide /Casadevall and Perfect 1998). Existing treatments are often inadequate for eradicating infection and have toxic side effects, and resistant strains are emerging. Novel approaches for the discovery of new antifungal targets and their inhibitors have been reported, but as of yet, none has led to therapeutic interventions (Fostel and Lartey 2000). Recently, several studies have suggested the sphingolipid pathway as a potential novel target for antifungal therapy (Mandala et al. 1998; Wills et al. 2000).

Sphingolipids are essential components of all eukaryotic membranes, and their presence or absence can have a major impact on cell viability and growth in both mammalian and yeast cells (Dickson and Lester 1999; Hannun and Luberto 2000). Although eukaryotic organ-

${ }^{6}$ Corresponding author.

E-MAIL delpoeta@musc.edu; FAX (843) 792-1627.

Article and publication are at www.genesdev.org/cgi/doi/10.1101/ $\operatorname{gad} .856001$. isms are characterized by the presence of sphingolipids, differences between yeast and mammals throughout the biosynthetic pathways have been described (Mandala et al. 1998; Wills et al. 2000). One of the fungus-specific steps is the synthesis of IPC from phytoceramide, regulated by the inositol-phosphoryl ceramide synthase 1 (Ipc1), encoded by the IPC1 gene (also called AUR1) (Heidler and Radding 1995). Concomitant to IPC formation, Ipc1 also produces diacylglycerol (DAG) and consumes phytoceramide. The importance of Ipcl therefore may be due not only to the formation of IPC itself, one of the more abundant sphingolipids in the membranes, but also to the regulation of phytoceramide, implicated in growth arrest and yeast stress responses (Jenkins et al. 1997; Chung et al. 2000), and DAG, a well-established mitogen and activator of protein kinase C (PKC) (Fig. 6).

Because IPC1 is both an essential gene and specific to different fungi (Heidler and Radding 1995; Kuroda et al. 1999; Heidler and Radding 2000), modulation of its expression may assume a critical role in vital biological functions. Importantly, in the specific case of an opportunistic pathogen (such as $C$. neoformans), alteration of these crucial functions could lead to an impaired patho- 
genicity by affecting host-fungus interaction, modifying the production of virulence traits (fungus factor), and/or altering the immune responses (host factor). A key factor for understanding the mechanisms by which Ipc1 exerts its cellular effects is the modulation of its expression by a promoter that allows the study of both up- and downregulation of IPC1. The C. neoformans GAL7 promoter allows these studies because even under repressing conditions (glucose medium) transcription can still be detected (Del Poeta et al. 1999a). Moreover, C. neoformans is ideally suited for studies of fungal pathogenesis because it has a defined sexual life cycle (Kwon-Chung and Popkin 1976), stable isogenic haploid strains of opposite mating type are available (Moore and Edman 1993), it is amenable to genetic analysis, transformation, gene disruption and regulation by homologous recombination (Toffaletti et al. 1993; Chang and Kwon-Chung 1994; Lodge et al. 1994), and virulence of strains can be readily assessed both in animal models and in in vitro assays (Perfect et al. 1993; Chaturvedi et al. 1996; Alspaugh et al. 1997; Odom et al. 1997; Franzot et al. 1998; Cruz et al. 1999; Del Poeta et al. 1999b; Fries et al. 1999; Liu et al. 1999).

Here, we regulated the expression of the $C$. neoformans IPC1 gene under the GAL7 promoter, and we report for the first time that a gene of the sphingolipid pathway has a role in pathogenesis. In particular, we find that modulation of Ipc1 levels in vitro has important effects on melanin pigmentation. Down-regulation of IPC1 generated a strain no longer pathogenic in a rabbit model of cryptococcal meningitis. Importantly, we found that a decreased Ipc1 level impaired the $C$. neoformans growth into J774.16 murine macrophage-like cell line. Finally, we found that an acidic environment significantly altered growth of $C$. neoformans with low Ipc1 activity. Our studies clearly indicate an important role for Ipc1 in pathogenesis by modulating different virulence traits of $C$. neoformans.

\section{Results}

\section{Cloning the IPC1 gene under GAL7 regulation}

Because the IPC1 gene is essential, a key factor for understanding the mechanisms by which Ipc1 mediates its cellular effects is the need to modulate its expression by a promoter that allows both up- and down-regulation of IPC1. The C. neoformans GAL7 promoter allows these studies because even under repressing conditions (glucose medium) the transcription of the gene still can be detected (Del Poeta et al. 1999a). Therefore, we placed IPC1 under the control of the GAL7 promoter by homologous recombination in the ade2 strain M001 using the plasmid pGAL7::IPC1/ADE2. Out of $30 \mathrm{ADE}^{+}$transformants, two showed that the endogenous IPC1 gene had been replaced by the pGAL7::IPC1/ADE2 construct (Fig. 1). The two transformants (\#10 and \#13) in which the GAL7::IPC1/ADE2 fusion gene integrated at the IPC1 locus, and at no other ectopic sites, were chosen and designated the GAL7::IPC1 strains \#10 and \#13, re- spectively. Transformant \#10 showed a double crossover with insert of plasmid loop (or single crossover followed by a double crossover event). Note that transformant \#2 showed a single crossover event at the upstream region of the IPC1 locus and an ectopic integration. We have used the GAL7::IPC1 strains in which IPC1 expression can be regulated to study the effects of different levels of Ipcl activity on biology and pathogenesis of C. neoformans.

\section{Expression levels of IPC1 under inducing and repressing conditions}

The expression levels of the IPC1 gene under the GAL7 promoter were determined at its transcription and translation levels by determining both mRNA and Ipc1 activity. The IPC1 mRNA levels were determined by semiquantitative RT-PCR in both GAL7::IPC1 strains. Figure 2A shows that the IPC1 mRNA expression level after 6 $\mathrm{h}$ on galactose medium was increased $\sim 50$ - and $\sim 30$-fold in the GAL7::IPC1 strains \#10 and \#13, respectively, and the expression was decreased after $24 \mathrm{~h}$ of induction. We were unable to determine the expression level under repressing glucose conditions because the basal level of IPC1 mRNA in wild-type cells is extremely low, although overexposure to UV light allowed the detection of IPC1 mRNA in the wild-type cells but not the repressed ones (data not shown). No significant differences were found in actin mRNA expression levels. Because these portions of the $3^{\prime}$ regions of these two genes contain two small introns (52 bp for the IPC1 gene and $51 \mathrm{bp}$ for the actin gene), we could establish that the RT-PCR products derived from cDNA and not contaminating genomic DNA, based on the sizes of the RT-PCR products.

In vitro Ipc1 activity levels were determined in the wild-type H99 and GAL7::IPC1 strains using NBD-C6ceramide as a substrate. Ipc1 activity was significantly increased under galactose-inducing medium after $24 \mathrm{~h}$ (Fig. 2B), whereas no significant differences were found after $30 \mathrm{~min}, 1 \mathrm{~h}, 3 \mathrm{~h}$, and $6 \mathrm{~h}$ of incubation /data not shown). Decreased Ipc1 activity was observed under glucose-repressing conditions, although residual Ipc1 activity is still available to support cell viability. In addition, the in vitro Ipc1 activity levels were determined in a prototrophic transformant (M001 + genomic ADE2) under glucose and galactose growth conditions. No differences were found between this prototrophic transformant and the parental H99 strain (data not shown).

Modulation of IPC1 gene expression did not exert any effect on cell growth at both $30^{\circ} \mathrm{C}$ and $37^{\circ} \mathrm{C}$. In fact, the growth curves relative to each strains and conditions (temperature and/or Ipc1 levels) were superimposable (data not shown).

\section{IPC1 regulates melanin production in C. neoformans}

Melanin production is considered one of the virulence factors in pathogenic fungi. In fact, melanin is thought to provide cellular protection from oxygen- and nitrogen- 

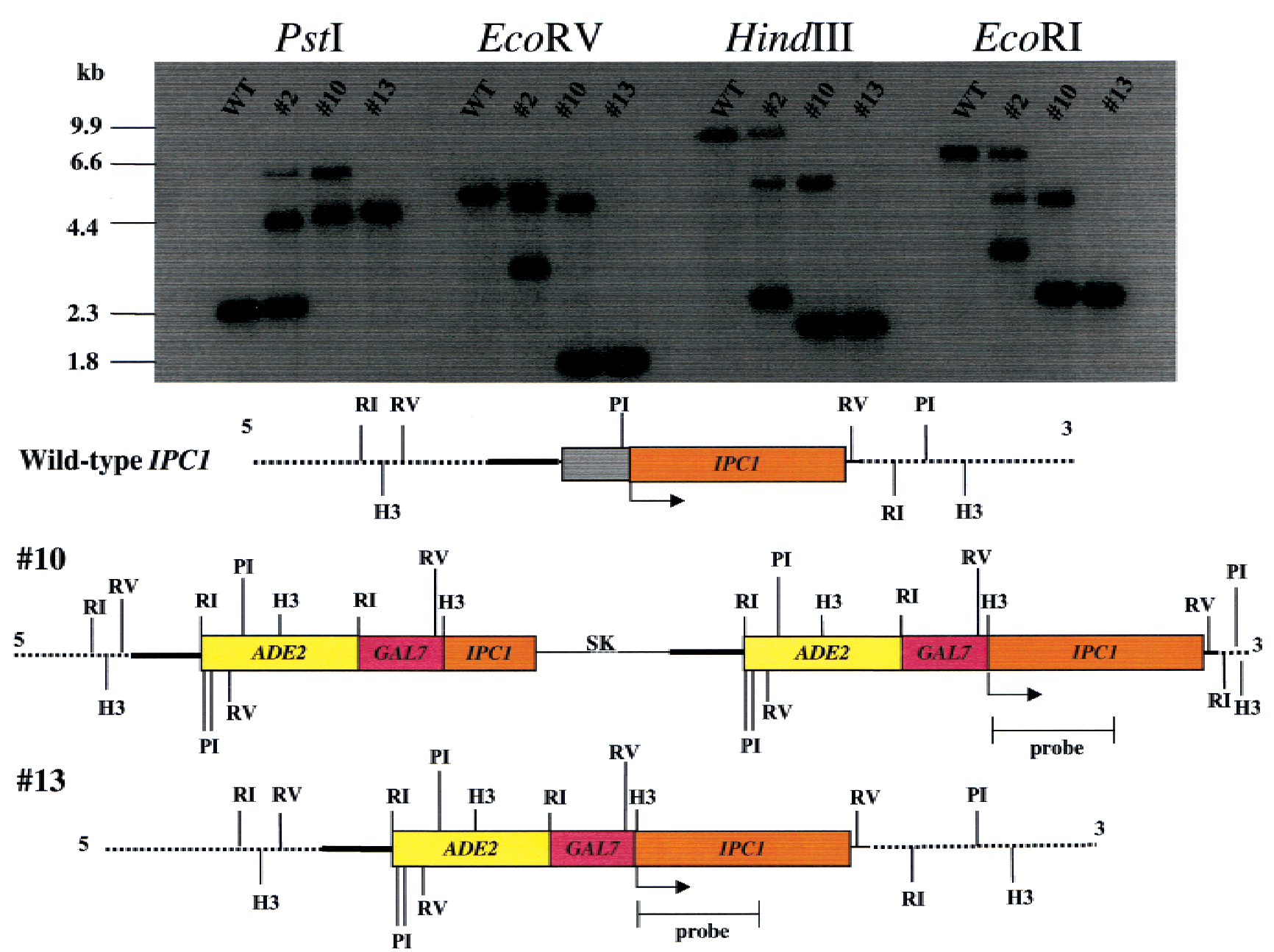

Figure 1. Replacement of the endogenous wild-type IPC1 with pGAL7::IPC1/ADE2. Southern analysis of wild-type strain H99 and transformants with genomic DNA digested with PstI (PI), EcoRV (RV), HindIII (H3), and EcoRI (RI), as indicated. Transformant \#2 showed a single crossover event at the upstream region of the IPC1 locus. Transformant \#10 showed a double crossover event with insert of plasmid loop (or single crossover followed by a double crossover event). Transformant \#13 showed a double crossover event. Confirmation of the GAL7::IPC1 gene replacement was also confirmed by PCR analysis using different primer combinations (data not shown). (SK) pBluescript SK plasmid.

reactive species produced by host immune cells (Wang et al. 1995). Indeed, melanin-deficient mutant strains show reduction of virulence in animal models of cryptococcosis (Kwon-Chung et al. 1982; Rhodes et al. 1982; Alspaugh et al. 1997; Alspaugh et al. 1998; Franzot et al. 1998; Perfect et al. 1998; Williamson et al. 1998; Doering et al. 1999; Nosanchuk et al. 1999). Recent studies have implicated DAG-induced activation of PKC in the stimulation of this process in mammalian cells (Agin et al. 1991; De Oliviera et al. 1996; Gilchrest et al. 1996). Because DAG is one of the products of the Ipcl reaction, we wondered whether the modulation of IPC1 expression would exert an effect on melanin production in $C$. neoformans.

By using a quantitation method previously described (Alspaugh et al. 1997), we addressed whether the activity of phenoloxidase (the key cryptococcal enzyme involved in melanin production) was affected in the GAL7::IPC1 strain (\#10) under inducing and repressing conditions.
We found that melanin production was reduced by $60 \%$ in the GAL7::IPC1 strain under glucose-repressing conditions, and it was increased by $\sim 80 \%$ under galactoseinducing conditions (Fig. 3A). These data show that altered Ipc1 activity regulates melanin production in $C$. neoformans. These results were confirmed using a second independent GAL7::IPC1 transformant (\#13) (data not shown).

\section{Down-regulation of Ipc1 renders C. neoformans nonpathogenic}

Because we found that Ipcl could be involved in the modulation of melanin production, we next tested whether Ipc1 down-regulation would affect the pathogenicity in the rabbit animal model of cryptococcal meningitis, in which glucose is available as a carbon source instead of galactose. 
Figure 2. (A) In vitro quantitative analysis of $C$. neoformans IPC1 mRNA in H99 and GAL7::IPC1 strains. The isogenic wild-type strain H99 (WT) and the GAL7::IPC1 strains were grown on galactose (inducing conditions). RNA was extracted at different time points (30 $\mathrm{min} ; 1$, $3,6$, and $24 \mathrm{~h})$, converted to cDNA, and amplified with primers directed to IPC1 or actin genes. RT-PCR products were separated by electrophoresis in a $1 \%$ agarose gel and stained with ethidium bromide. The IPC1 and actin RT-PCR products are 926 and $543 \mathrm{bp}$, as indicated. (B) In vitro quantitative analysis of Ipc1 activity in $C$. neoformans wild-type (H99) and GAL7::IPC1 strains grown on glucose (repressing conditions) and galactose (inducing conditions). (Left) The Ipc1 synthase in vitro activity was determined as conversion of NBD-C6-ceramide (NBD-C6-CER) into NBC-C6-IPC by thin layer chromatography (TLC) analysis. (Right) Numerical analysis of Ipcl activity from the TLC is reported.
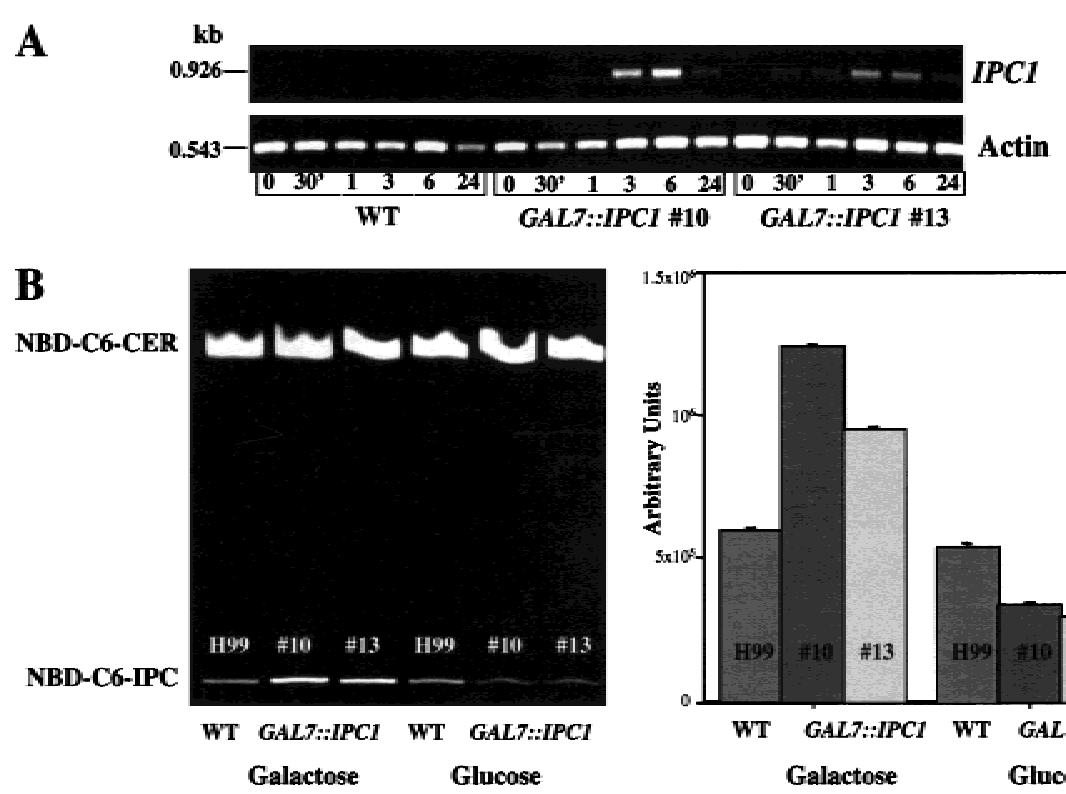

To test this hypothesis, we inoculated intrathecally immunosuppressed rabbits with the $C$. neoformans wild-type or GAL7::IPC1 strains. Survival of C. neoformans in the central nervous system (CNS) was determined by removal of cerebral spinal fluid (CSF) and quantitation of colony-forming units (CFU) by serial dilution and plating. Several studies have established the value of this experimental model in studying C. neoformans virulence (Perfect et al. 1980; Lodge et al. 1994; Alspaugh et al. 1997; Odom et al. 1997; Del Poeta et al. 1999a; Del Poeta et al. 1999b; Wang and Heitman 1999; Yue et al. 1999).
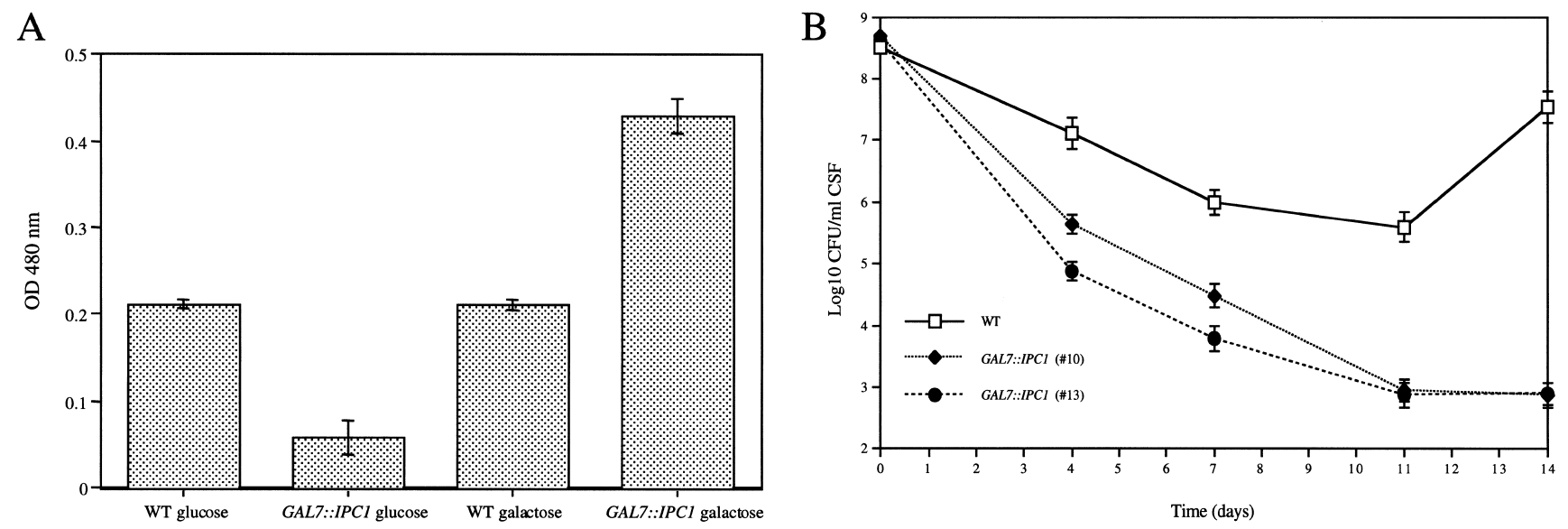

Figure 3. (A) IPC1 regulates melanin pigmentation in C. neoformans. The wild-type (WT) and GAL7::IPC1 strains were grown for 16 $\mathrm{h}$ at $30^{\circ} \mathrm{C}$ under inducing and repressing conditions. Cells were permeabilized with toluene:ethanol, incubated for $16 \mathrm{~h}$ in presence of $L$-dopamine, and the cellular phenoloxidase activity was assayed spectrophotometrically by measuring the appearance of melanin in the supernatant by the change in absorbance at $480 \mathrm{~nm}$. The $A_{480}$ of samples to which $L$-dopamine had been added was compared with the blank sample in which no $L$-dopamine had been added. Data represent geometric means \pm standard deviations of three separate experiments. (B) IPC1 regulates virulence of $C$. neoformans in a rabbit animal model of cryptococcal meningitis. Rabbits (three for each strain) were immunosuppressed with steroids and inoculated with $3 \times 10^{8}$ cells. CSF was removed on days 4, 7, 11, and 14 following inoculation, and the number of surviving organisms was determined by serial dilutions and plating on YPD medium. Each data point represents the geometric means of all cultures for each strain, and the standard deviations of the mean are indicated. 
The intracellular growth of the GAL7::IPC1 strain is impaired in J774.16 murine macrophage-like cells under glucose-repressing conditions

C. neoformans is a facultative intracellular pathogen in vivo (Feldmesser et al. 2000). To investigate the mechanism by which Ipc1 contributes to virulence, we explored the effect of reduced Ipc1 on macrophage intracellular growth. We infected the J774.16 murine macrophage-like cell line with the $C$. neoformans wild-type H99 and GAL7::IPC1 strains and monitored the fungal growth inside the host cells under glucose-repressing and galactose-inducing conditions. We found that under glucose conditions, the GAL7::IPC1 strain replicated slower than the wild type, whereas under galactose conditions, it replicated faster than the wild type (Fig. 4A). In addition, we found that under glucose-repressing conditions the GAL7::IPC1 cells remained in a tight cluster after lysis of the macrophage-like cells (data not shown), whereas they appeared to disperse under galactose conditions (Fig. 4B). These findings indicated to us that ex- pression of IPC1 is required for normal in vivo growth, by modulating both replication and diffusion of the infection. Moreover, we observed that the GAL7::IPC1 strain produced a larger phagolysosome in galactoseinducing conditions (Fig. 4C). Taken together, these observations indicate that IPC1 regulates the growth of $C$. neoformans in J774.16 murine macrophage-like cell line.

Down-regulation of IPC1 gene increases the sensitivity to low $\mathrm{pH}$

As shown in Figure 4C, the intracellular growth of $C$. neoformans into macrophages occurs in the phagolysosome, an acidic environment. Therefore, we wondered whether the lack of replication of the Ipc1 down-regulated cells in the phagolysosome was due to a lower tolerance of acidic $\mathrm{pH}$. Thus, we monitored the in vitro growth of the GAL7::IPC1 and wild-type H99 strains at $\mathrm{pH}$ 4.0, under glucose-repressing and galactose-inducing
$\mathbf{A}$

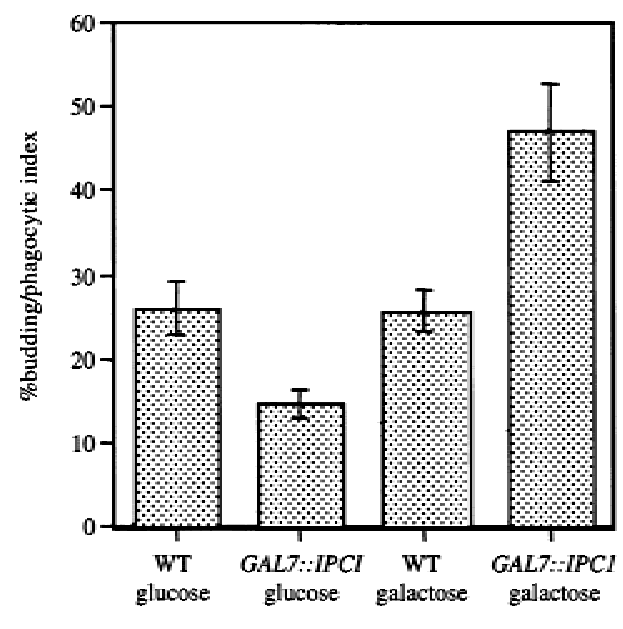

B

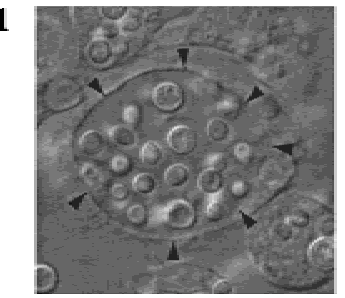

3

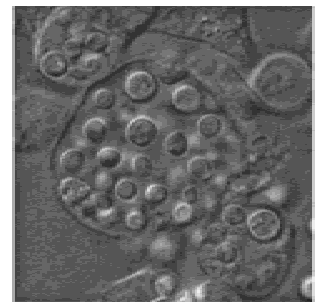

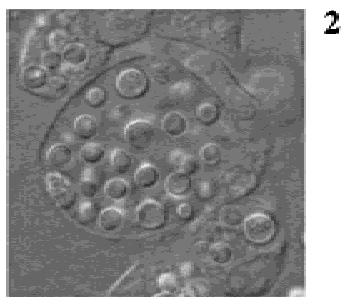

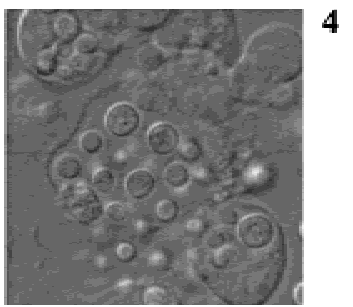

2

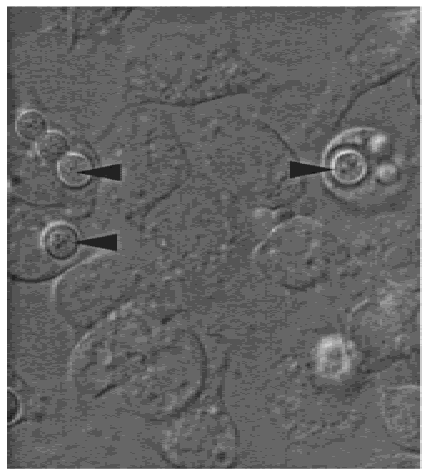

WT galactose

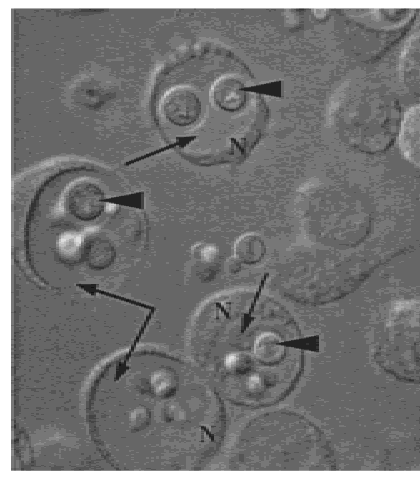

GAL7::IPCI galactose

Figure 4. IPC1 regulates intracellular growth in the J774.16 macrophage-like cell line. $(A)$ Five hours postinoculation, buds were counted only in yeast cells inside the macrophages (\% budding/phagocytic index). Counts are geometric means \pm standard deviations of four different fields. (B) Lysis of macrophage infected by the GAL7::IPC1 strain on galactose medium at $18 \mathrm{~h}$ postinoculation. (Frame 1) Intact macrophage. Arrowheads indicate the phagolysosome. (Frames 2-4) Lysis of macrophage. (C) Phagolysosomes size. Arrowheads indicate yeast cells inside the phagolysosome, whereas long arrows in the last right panel indicate the larger phagolysosome. (N) nucleus. Cells were photographed at $\sim 18 \mathrm{~h}$ postinoculation. 
conditions. As shown in Figure 5, we found that during the exponential proliferation phase, the growth of the $C$. neoformans GAL7::IPC1 strain (\#10) in glucose was reduced by $\sim 20$ - and 15-fold compared with the wild type at $24 \mathrm{~h}$ and $36 \mathrm{~h}$ of incubation, respectively. However, it is interesting to note that the cell concentrations at the stationary phase were the same for both strains.

\section{Discussion}

The study of the role and function of essential genes in yeast is particularly difficult because often, under repressing conditions, strains are not viable. In our previous studies we showed that the GAL7 promoter, when used for the regulation of essential genes, maintains viable cells (Del Poeta et al. 1999a) and can be successfully used in $C$. neoformans to study its virulence traits and pathogenesis. By regulating the IPC1 gene under the GAL7 promoter, we showed that down-regulation of IPC1 impairs pathogenicity of C. neoformans. Indeed, we found that down-regulation of IPC1 significantly lowers melanin production, in vivo growth in macrophages, and diffusion ability of cell progenies. Our results indicate that Ipc1 exerts a major role in the pathogenesis of $C$. neoformans through crucial and perhaps diverse mechanisms.

First, we addressed the question whether IPC1 expression has a role in virulence traits of $C$. neoformans, such as melanin pigmentation. We found that overexpression of the IPC1 gene induces more melanin production, whereas down-regulation decreases melanin pigmentation. Melanin synthesis in C. neoformans is catalyzed by a single laccase gene (Williamson et al. 1998). Its product, a laccase, converts exogenous diphenolic substrates through a series of autooxidation reactions to the final pigmented product (Polacheck and Kwon-Chung 1988). Melanin has been proposed as a virulence factor for $C$. neoformans because melanin-deficient mutants are not pathogenic in the animal models of cryptococcosis (Kwon-Chung et al. 1982; Wang et al. 1995; Salas et al. 1996; Williamson et al. 1998; Nosanchuk et al. 1999).

C. neoformans melanizes during infection, and it has been suggested that the neurotrophism of this pathogenic fungus is associated with its ability to produce melanin from cathecolamines, which are found in concentrated amounts in the CNS (Polacheck et al. 1990). Recent evidence indicates that this pigment protects the fungus against immune defense mechanisms, possibly because of its autooxidants properties, and/or because of its ability to mask potential antigens (Wang et al. 1995; Nosanchuk et al. 1998; Doering et al. 1999; Liu et al. 1999; Schnitzler et al. 1999; Casadevall et al. 2000). Interestingly, it has been proposed that melanin production by $C$. neoformans could affect cytokines release from the host immune defense (Huffnagle and McNeil 1999; Barluzzi et al. 2000). Several studies have proposed that DAG stimulates melanogenesis in human, poikothermic vertebrates, and in Skh-2 pigmented hairless mice through activation of PKC (Agin et al. 1991; De Oliviera et al. 1996; Gilchrest et al. 1996). Whether this mechanism is also involved in C. neoformans is not known. Because Ipc1 regulation directly modulates DAG formation, the hypothesis that the DAG-PKC-melanin connection occurs also in C. neoformans is attractive, and we will investigate this possibility in the future.

Because Ipc1 was involved in the modulation of melanin production, we studied whether Ipc1 down-regulation affected the pathogenicity in the rabbit animal model of cryptococcal meningitis, in which glucose is available as a carbon source instead of galactose. Glucose level in the CSF is $~ 50 \%-60 \%$ of glucose level in the blood, which is $80 \mathrm{mg} / 100 \mathrm{~mL}$ or $800 \mu \mathrm{g} / \mathrm{mL}$. At glucose concentrations equal, below, and above blood level, the in vitro Ipc1 activity of the GAL7::IPC1 strains (\#10 and $\# 13$ ) is similarly reduced by approximately fourfold com-
Figure 5. IPC1 expression modulates in vitro growth under low-pH stress condition. C. neoformans wild-type (WT) and GAL7::IPC1 strains grown on YP medium (pH 4.0), supplemented with $2 \%$ glucose or $2 \%$ galactose. Colony forming units/ $\mathrm{mL}(\mathrm{CFU} / \mathrm{mL})$ are geometric means $\pm \mathrm{SD}$ of three separate experiments.

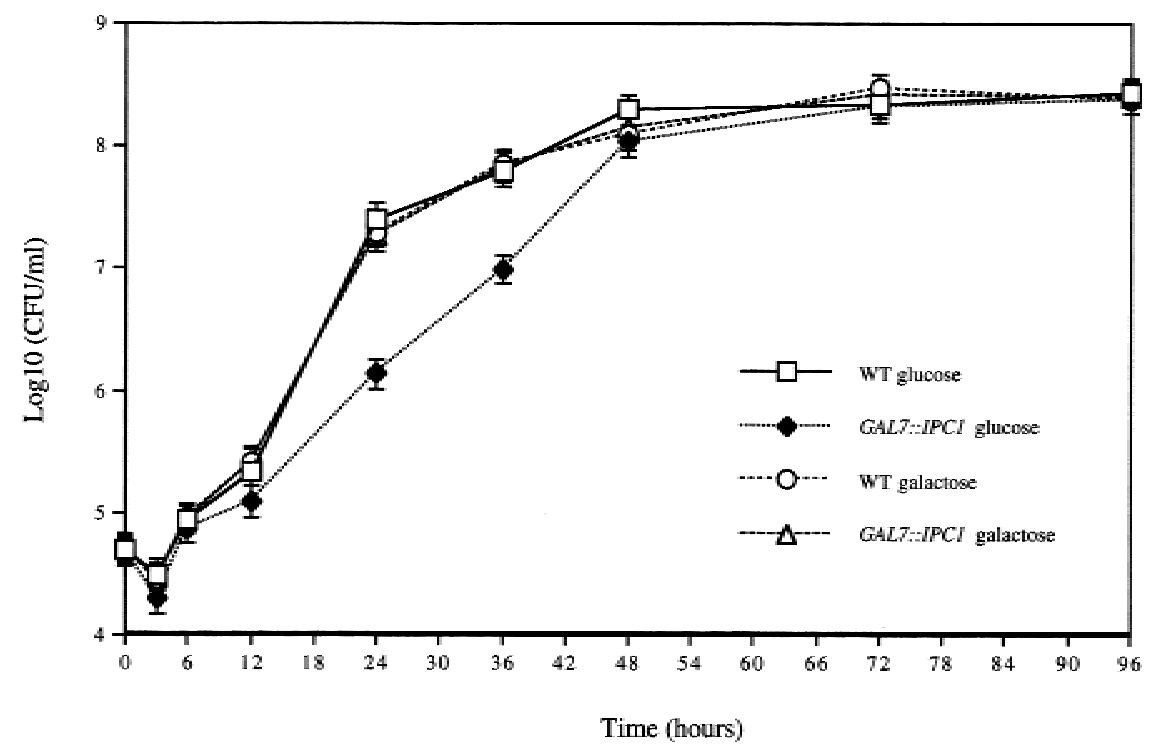


pared with the wild-type H99 (data not shown). These observations lead us to hypothesize that if full expression of IPC1 is required in vivo, then the survival rate of the GAL7::IPC1 strains will be impaired. To test this hypothesis, we inoculated immunosuppressed rabbits intrathecally with the $C$. neoformans wild-type or GAL7::IPC1 strains. By testing two independent C. neoformans GAL7::IPC1 transformants, we observed that these strains are no longer pathogenic in the rabbit animal model of cryptococcal meningitis. Because the in vitro growth of the GAL7::IPC1 strains is not impaired under normal conditions at $30^{\circ} \mathrm{C}$ and $37^{\circ} \mathrm{C}$, and at low and high glucose concentrations (data not shown), the data obtained from the animal correlate the pathogenic trait of $C$. neoformans to its growth in vivo. Our results for the first time implicate IPC1 in the virulence of a human pathogen.

One major factor for $C$. neoformans to produce infection is its ability to grow in the host cells (Feldmesser et al. 2000). Therefore, to investigate this mechanism, we studied the effects of the up- and down-regulation of the IPC1 gene on intracellular growth in the J774.16 murine macrophage-like cell line. As shown in Figure 4A, the replication time of the GAL7::IPC1 strain in glucose medium was reduced compared with the wild type. In galactose medium, the replication time of the GAL7::IPC1 strain was increased. We found by electron microscopy that the phagolysosome membrane is not intact (Feldmesser et al. 2000). Therefore, we hypothesize that small molecules (e.g., glucose or galactose) will also enter the phagolysosome. Recently, it has been shown that survival and growth of C. neoformans in macrophages occur in the acidic phagolysosome (Levitz et al. 1999). Unlike other pathogens, such as Mycobacterium tuberculosis and Histoplasma capsulatum, C. neoformans does not regulate the $\mathrm{pH}$ of the phagolysosome, and it is resistant to the action of macrophage lysosomal enzymes (Howard 1961; Diamond and Bennett 1973; Levitz and Tabuni 1991; Levitz et al. 1997).

Therefore, we next investigated the effect of IPC1 regulation on the ability of $C$. neoformans to grow in acidic conditions. In our case, down-regulation of IPC1 conferred a defect on in vitro growth of GAL7::IPC1 strain at acidic $\mathrm{pH}$, whereas it does not affect growth under neutral pH (7.0) (data not shown). Because these conditions are similar to those in the phagolysosome of the J774.16 macrophage-like cell line, our findings indicate that the down-regulation of IPC1 confers a growth defect in vivo through a $\mathrm{pH}$-dependent mechanism. This hypothesis is further supported by the observation that, after $5 \mathrm{~h}$ post-infection, the GAL7::IPC1 strain into J774.16 cells is able to replicate faster than the wild-type cells under galactose-inducing conditions (Fig. 4A).

The involvement of the IPC1 gene in the adjustment to $\mathrm{pH}$-induced stress may indicate a more general role of Ipc1 in regulation of other stress responses. Indeed, we found that Ipc1 levels also regulate the response to osmotic stress (data not shown). One possible mechanism by which modulation of Ipc1, and therefore sphingolipid levels, can regulate $\mathrm{pH}$ and osmotic stress is through the alteration of the physical properties of the plasma membrane (Levine et al. 2000). The acyl chains, the association with sterols, and the capacity for hydrogen bonding lead to sphingolipids promoting a more compact, thicker, and less permeant bilayer.

Such a role for sphingolipids is supported by the determination that yeast cells lacking complex sphingolipids are not viable (Lester et al. 1993; Nagiec et al. 1993; Hashida-Okado et al. 1996). In our studies, we found that the GAL7::IPC1 strain produces less complex sphingolipids under glucose-repressing conditions /data not shown), indicating that the resulting plasma membrane may be more permeant to solutes and cations and, thus, be in an altered intracellular homeostasis of $\mathrm{Na}^{+}$and $\mathrm{H}^{+}$.

To produce chronic infection, microbial pathogens must escape host immune responses, and infection by $C$. neoformans is typically chronic. In early infection, $C$. neoformans cells were found predominantly in the intracellular compartment. A shift toward extracellular predominance occurred by $\sim 24 \mathrm{~h}$ of infection and was accompanied by macrophage cytotoxicity and disruption (Feldmesser et al. 2000). Interestingly, after macrophage disruption we observed that the release of the GAL7::IPC1 strain in glucose differed from that in galactose and the wild-type H99. Cells were compacted, forming a cluster of a "grape-like" shape (data not shown), whereas the GAL7::IPC1 on galactose and the wild type were dispersed as single cells after the macrophage disruption (Fig. 4B). Perhaps this decreases the ability of the organism to cause tissue damage because the cells are clumped together and possibly less likely to infect other macrophages.

As a direct consequence, it is reasonable to hypothesize that such yeast cells would not be able to readily infect other host cells, and, thus, they would be easily attacked by the immune responses, resulting in a decreased dissemination of the infection.

Although the IPC1 gene has been isolated in several microorganisms, the biological roles of this "fungus-specific step" have not been described. Our studies define novel functions for Ipc1 in pathogenesis of the opportunistic pathogen $C$. neoformans. In particular, we find that modulation of IPC1 expression regulates virulence traits, such as melanin pigmentation. Also, IPC1 downregulation impairs pathogenicity of $C$. neoformans in the animal model and significantly decreases its intracellular growth in the phagolysosome of $\mathbf{J 7 7 4 . 1 6}$ macrophagelike cells. Finally, we find that down-regulation of the IPC1 gene confers a defect on in vitro growth at low $\mathrm{pH}$, and, because this environment is similar to that in the phagolysosome of $\mathrm{J774}$ cells, our results indicate that down-regulation of IPC1 confers a growth defect in vivo through a $\mathrm{pH}$-dependent mechanism. These findings are summarized in the model presented in Figure 6. Our ongoing epistasis analysis begins to determine the mechanisms of how the sphingolipid pathway regulates virulence in pathogenic fungi and, for the first time, implicates Ipc1 in the virulence of a human pathogen. Finally, these results should prompt the development of novel antifungal drugs against this fungus-specific target. 


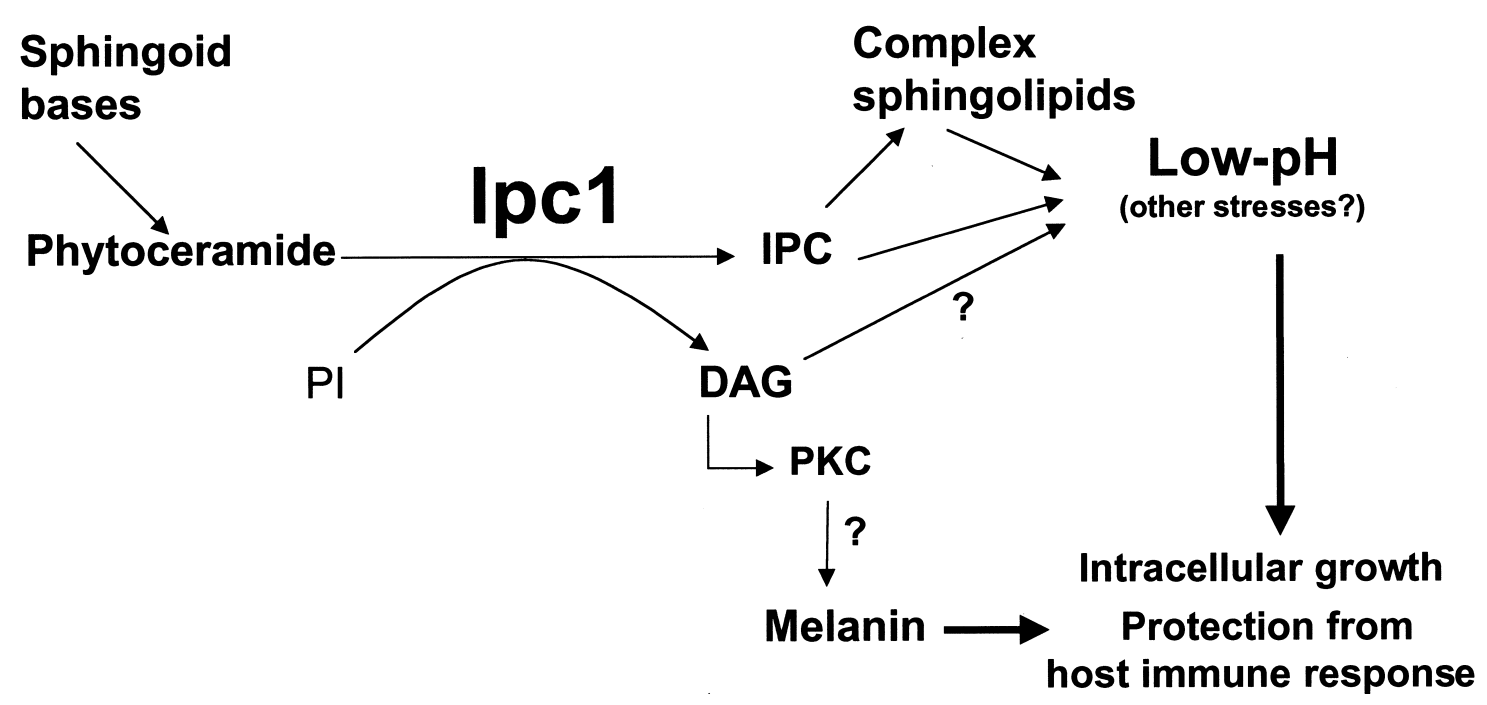

Figure 6. A model for the role of Inositol-phosphoryl ceramide synthase 1 (Ipc1) in regulation of virulence traits and pathogenesis of C. neoformans. Ipc1 transfers the phosphoryl-inositol moiety from phosphatidylinositol (PI) to phytoceramide, forming inositolphosphoryl ceramide (IPC) and diacylglycerol (DAG).

\section{Materials and methods}

\section{Strains and growing media}

C. neoformans var. grubii serotype A strain H99 (wild-type) and M001 strain, an ade2 isogenic derivative of H99, were used in this study. A GAL7::IPC1 strain was created from M001. A synthetic medium, containing $6.7 \mathrm{~g} / \mathrm{L}$ of Yeast Nitrogen Base (YNB) without amino acids, $1.3 \mathrm{~g} / \mathrm{L}$ amino acid mix lacking adenine, $180 \mathrm{~g} / \mathrm{L}$ sorbitol, $20 \mathrm{~g} / \mathrm{L}$ galactose, and $20 \mathrm{~g} / \mathrm{L}$ agar, was used for selecting the GAL7::IPC1 strain obtained from biolistic transformation. C. neoformans H99, M001, and GAL7::IPC1 strains were routinely grown on yeast extract peptone dextrose (YPD) medium. Yeast extract peptone (YP) supplemented with $20 \mathrm{~g} / \mathrm{L}$ glucose or $20 \mathrm{~g} / \mathrm{L}$ galactose was used for down- and upregulated IPC1 expression, respectively.

\section{Preparation of genomic DNA}

DNA was isolated from C. neoformans strains as follows: $10 \mathrm{~mL}$ of mid- to late-log phase C. neoformans grown in appropriate media was pelleted and washed three times in sterile deionized water (SDW). Cells were suspended in $0.5 \mathrm{~mL}$ TES buffer (10 $\mathrm{mM}$ Tris at $\mathrm{pH} 7.5,1 \mathrm{mM}$ EDTA at $\mathrm{pH}$ 8.0, $1 \%$ sodium dodecyl sulfate [SDS]). Then, $0.2 \mathrm{~mL}$ of $0.5-\mathrm{mm}$ acid-washed glass beads was added and samples were incubated for $1 \mathrm{~min}$ on ice, followed by homogenization for $1 \mathrm{~min}$ by mini Bead-Beader-8 (BioSpec). Cells were incubated for $10 \mathrm{~min}$ at $70^{\circ} \mathrm{C}$, briefly vortexed, and, after adding $200 \mu \mathrm{L}$ of $3 \mathrm{M}$ potassium acetate and $150 \mu \mathrm{L}$ of $5 \mathrm{M} \mathrm{NaCl}$, cells were incubated for $20 \mathrm{~min}$ on ice. After centrifugation for $20 \mathrm{~min}$ in a microfuge at $13,000 \mathrm{rpm}$, the aqueous phase $(-600 \mu \mathrm{L})$ was transferred to a new tube, $300 \mu \mathrm{L}$ of $30 \%$ PEG 6000 was added, and samples were incubated for $10 \mathrm{~min}$ on ice. Precipitated DNA was collected by centrifugation at 13,000 $\mathrm{rpm}$, resuspended in $40 \mu \mathrm{L} \mathrm{TE}(\mathrm{pH} 8.0)$, and stored at $-20^{\circ} \mathrm{C}$.

Cloning the C. neoformans IPC1 gene under the GAL7 promoter

The C. neoformans IPC1 gene has been isolated. However, the sequence submitted to the GenBank (accession \#AAD28749) is truncated at the promoter region. To isolate the promoter and the untranslated upstream regions, the following strategy was used. Amplification of a part of C. neoformans IPC1 from genomic DNA was performed by PCR using the following primers: IPC1-5: 5'-ATG TCC GCC ATC CGC GCA CTC-3' and IPC1-3: 5'-GAG CTA TTC TCT GAA GCC ACC-3'. PCR conditions were $5 \mathrm{~min}$ at $95^{\circ} \mathrm{C}(1 \mathrm{cycle}) ; 50 \mathrm{sec}$ at $93^{\circ} \mathrm{C}, 50 \mathrm{sec}$ at $50^{\circ} \mathrm{C}, 80 \mathrm{sec}$ at $72^{\circ} \mathrm{C}(30$ cycles $) ; 10 \mathrm{~min}$ at $72^{\circ} \mathrm{C}(1 \mathrm{cycle})$. This amplification strategy produced a 1450 -bp fragment that was cloned into pCRII-TOPO vector (Invitrogen), sequenced, and named pCR-CnIPC1. Then, a genomic library of H99 in EMBL3 was screened with the PstI- and EcoRV-digested 1.4-kb probe fragment from the pCR-CnIPC1 plasmid. Positive plaques were then purified through three rounds of repeated screening. One strongly positive $\lambda$ clone (\#2.1) was purified using the plate lysate method, as described by Fritsch (Sambrook et al. 1989). The 2.1 genomic clone was further digested with $N c o$ I and EcoRV, generating $2.1-\mathrm{kb}$ and $0.7-\mathrm{kb}$ hybridizing fragments. The $0.7-\mathrm{kb}$ fragment corresponded to the $3^{\prime}$ end of the IPC1 gene, whereas the $2.1-\mathrm{kb}$ fragment contained the $5^{\prime}$, promoter, and upstream untranslated regions of the IPC1 gene. This $2.1-\mathrm{kb}$ fragment was extracted from agarose gel using the Qiagen Gel Extraction Kit (Qiagen), partially sequenced in both directions, and shown to be the $5^{\prime}$, promoter, and upstream regions of the $C$. neoformans IPC1 gene. Presumptive TATA and CAAT boxes were present at $-199 \mathrm{bp}$ and $-157 \mathrm{bp}$ from the ATG start site, respectively (GenBank accession no. AY007247).

The $\mathrm{p} G A L 7:: I P C 1 / A D E 2$ construct was generated by using a series of molecular manipulations involving the IPC1 gene, the 585-bp C. neoformans GAL7 promoter from serotype D, strain 3501, and the 3000-bp ADE2 marker genomic DNA fragment obtained from serotype A, strain H99. (1) Fragment A (526 bp) was generated by PCR using IPC1 $\lambda$ DNA (clone 2.1) as a template and the primers \#IPC-10, 5'-CTCA GGTACC TTA TCC CCA CTT GAA AGA GCT CG-3', and \#IPC-11, 5'-GCGA GAATTC AAG ACT ATC TTC ACG GCC AGC-3', containing

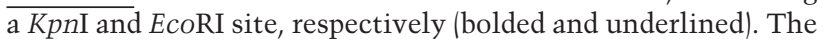
526-bp fragment contains a sequence corresponding to the upstream untranslated region of the IPC1 promoter.

This fragment was then digested with KpnI and EcoRI, pro- 
ducing fragment B (518 bp). (2) Fragment C (1104 bp) was generated using IPC1 $\lambda$ DNA (clone 2.1) as a template and the primers \#IPC-12, 5'-GTAT AAGCTT ATG TCC GCC ATC CGC GCA CTCAC-3', and \#IPC-13, 5'-GACA TCTAGA CCT CCC ACT GTA TCT GAT CAA CG-3', which contain sequence homologous to the $5^{\prime}$ and internal regions of IPC1, respectively. The primers \#IPC-12 and \#IPC-13 contain a HindIII and $\mathrm{XbaI}$ site, respectively (bolded and underlined). This fragment was then digested with HindIII and XbaI, producing fragment D (1092 bp). (3) The GAL7 promoter was amplified from the plasmid pAUG-MF, made by Wickes and Edman (1995), using primers 6C, 5'-CAGG GAATTC GTG GAA AGA AGC AGG TCT TGT CGA-3', and 6H, 5'-ATTA AAGCTT TCT CAA GAG GGG ATT GAG CGC TGA-3', containing an EcoRI and HindIII site, respectively. This fragment was then cleaved with EcoRI and HindIII, generating fragment E (585 bp). (4) Fragment B (upstream untranslated region) was cloned into the KpnI and EcoRI sites of an $\mathrm{SK}+$ pBluescript vector, generating plasmid \#1. (5) Fragment D (5'-region of IPC1 gene) was combined with fragment $\mathrm{E}$ (GAL7 promoter), ligated, and cloned into the EcoRI and $X b a$ I sites of plasmid \#1, generating plasmid \#2. The resulting plasmid contains the upstream untranslated region of the IPC1 locus and the GAL7 promoter in frame with the ATG start site of the 5'-truncated IPC1 gene. (6) Finally, the EcoRI-restricted $A D E 2$ fragment was then inserted into the EcoRI site located at the 5 '-end of the GAL7 promoter to form pGAL7::IPC1/ADE2. This GAL7::IPC1 fusion construct was sequenced to make sure that no mutations were introduced by PCR manipulations.

\section{Biolistic transformation}

The pGAL7::IPC1-ADE2 plasmid was transformed into C. neoformans strain M001 using biolistic delivery of DNA, following the protocol described by Toffaletti et al. (1993). Transformants were grown on YNB-galactose without adenine (see above). Colonies were chosen randomly and purified. Thirty stable transformants were chosen and transferred in YPD plates. Then, $10 \mathrm{~mL}$ YPD broth cultures were inoculated with a single colony and incubated for $48-72 \mathrm{~h}$ at $30^{\circ}$. Genomic DNA preparations for PCR and/or Southern blot analysis of transformants were performed as described by Sambrook et al. (1989). The transformants showing integration of the GAL7::IPC1-ADE2 fusion construct at the IPC1 locus were chosen and designated GAL7::IPC1 strains (Fig. 1).

\section{In vitro growth studies}

From overnight YPD broth cultures of C. neoformans H99 and GAL7::IPC1 strains, cells were washed twice in SDW, resuspended, and diluted into $10 \mathrm{~mL}$ fresh YP broth with either glucose or galactose to a final density of $10^{4}$ cells $/ \mathrm{mL}$ and incubated at $250 \mathrm{rpm} / \mathrm{min}$ in a shaker incubator at $30^{\circ}$ and $37^{\circ} \mathrm{C}$. For in vitro growth kinetics under $\mathrm{pH}$ stress condition, YP broth $(\mathrm{pH}$ 4.0) was used.

Samples were taken from the tubes at various time points $(0$, 3, 6, 12, 24, 36, 48, 72, and $96 \mathrm{~h}$ ), diluted with SDW, and plated onto YPD plates for assessment of colony-forming units. All cultures were performed in triplicate.

\section{RNA extraction and RT-PCR}

From overnight YPD broth cultures of $C$. neoformans H99 and GAL7::IPC1 strains, cells were washed twice in SDW, resuspended, and diluted into $10 \mathrm{~mL}$ fresh YP broth with either glucose or galactose to a final density of $10^{6}$ cells $/ \mathrm{mL}$ and incubated in a shaker incubator at $250 \mathrm{rpm} / \mathrm{min}$ at $30^{\circ}$. Samples were taken from the tubes at various time points $(0$ and $30 \mathrm{~min} ; 1,3$, 6 , and $24 \mathrm{~h}$ ). Then, total RNA was prepared as described by RNeasy Mini-Kit (Qiagen, Cat. \#74104), following the mechanical disruption protocol for yeasts. First-strand synthesis of cDNA was performed using $1 \mu \mathrm{g}$ of total RNA for each group following the protocol described by SuperScript Preamplication System (GIBCO BRL). First-strand synthesis was made with oligo(dT) primer. Second-strand synthesis of the IPC1 gene was with specific primers IPC-15 (5'-CTA AGA GCT ATT CTC TGA AGC) and IPC-18 (5'-GAT ATA CCA ACG CTT TCC TTG), yielding a 926-bp fragment.

Because of the presence of a 52-bp intron in this region, this pair of primers yielded a 978-bp fragment when genomic DNA was used as template for PCR. Actin-specific primers AC-2 (5'CAG CTG GAA GGT AGA CAA AGA GGC) and AC-1 (5'CGC TAT CCT CCG TAT CGA TCT TGC) were used for the second-strand synthesis of the actin gene as a control, yielding a 543-bp fragment. Because of the presence of a 51-bp intron in this region, this pair of primers yielded a 594-bp fragment when genomic DNA was used as template for PCR. The analysis of mRNA levels of the IPC1 gene was performed with a second independent GAL7::IPC1 transformant. RT-PCR of control RNA was performed in each run of experiments.

\section{In vitro activity of Ipc1}

Ipc1 activity was measured by using the fluorescent ceramide analog NBD-C6-ceramide (Avanti Polar Lipids) as substrate and monitoring the formation of NBC-C6-IPC, as described by Fischl et al. (2000) with some modifications. Briefly, wild-type and GAL7::IPC1 C. neoformans strains were grown on YP-glucose and YP-galactose media in a shaker incubator for $24 \mathrm{~h}$ at $30^{\circ} \mathrm{C}$. Cells were harvested by centrifugation, washed with SDW, and the pellets were stored at $-80^{\circ} \mathrm{C}$. Cell pellets were resuspended in lysis buffer (25 mM Tris at pH 7.4, 5 mM EDTA, 1 mM PMSF [Sigma \# P-7626], and $10 \mu \mathrm{g} / \mathrm{mL}$ each Chymostatin [Sigma \#C7268], Leupeptin [Sigma \#L-2884], Antipain [Sigma \#A-6271], and Pepstatin A [Sigma \#P-4265]). Then, acid-washed glass beads (for a volume equal to $3 / 4$ of the cell suspension) were added, and cells were homogenized three times for $45 \mathrm{sec}$ using the Bead-Beader-8. After centrifugation at $2500 \mathrm{~g}$ for $10 \mathrm{~min}$ at $4^{\circ} \mathrm{C}$, supernatant $(\sim 100 \mu \mathrm{L})$ was transferred to a sterile $1.5-\mathrm{mL}$ microcentrifuge tube for proteins quantitation, which was determined by the method of Bradford (1976). Proteins from the cell lysates $(60-100 \mu \mathrm{g})$ were incubated for $30 \mathrm{~min}$ at $30^{\circ} \mathrm{C}$ in 50 $\mathrm{mM}$ bis-Tris- $\mathrm{HCl}$ buffer $(\mathrm{pH}$ 6.5) containing $1 \mathrm{mM}$ PI, $5 \mathrm{mM}$ Triton X-100, $1 \mathrm{mM} \mathrm{MnCl} 2,5 \mathrm{mM} \mathrm{MaCl}_{2}, 20 \mu \mathrm{M}$ NBD-C6ceramide in a final reaction volume of $100 \mu \mathrm{L}$. The reaction was terminated by the addition of $0.5 \mathrm{~mL}$ of $0.1 \mathrm{~N} \mathrm{HCl}$ in methanol. Chloroform $(1 \mathrm{~mL})$ and $1 \mathrm{M} \mathrm{MgCl}_{2}(1.5 \mathrm{~mL})$ were added, the solution was mixed, and the phases were separated by a $10-\mathrm{min}$ centrifugation at $1000 \mathrm{~g}$. The chloroform-soluble product, NBDIPC, was analyzed by analytical thin-layer chromatography (TLC) on silica gel 60 plates (EM Science) using the solvent system chloroform/methanol/water (65:25:4). NBD-IPC was identified and quantified by direct fluorescence using a Molecular Dynamics 840 STORM unit.

\section{Melanin production}

Phenoloxidase activity was assayed as described previously (Alspaugh et al. 1997) with minor modifications. Cells were inoculated from fresh cultures in YPD into YP broth with $2 \%$ glucose or $2 \%$ galactose and incubated for $16 \mathrm{~h}$ at $30^{\circ} \mathrm{C}$ in a shaking incubator. Cells were pelleted, washed once with liquid 
YNB $(6.7 \mathrm{~g} / \mathrm{L})$ without sugar, and resuspended in $10 \mathrm{~mL}$ of the same medium. Cells were incubated for an additional $7 \mathrm{~h}$ at $30^{\circ} \mathrm{C}$, pelleted, washed once with SDW, and resuspended in 50 $\mathrm{mM}$ sodium phosphate $(\mathrm{pH} 7.0)(1 \mathrm{~mL}$ sodium phosphate solution for each $100 \mathrm{mg}$ of cells, wet weight).

Toluene:ethanol $(1: 4, \mathrm{v} / \mathrm{v}), 100 \mu \mathrm{L}$ per $1 \mathrm{~mL}$ of cell suspension, was added to permeabilize the cells, and the mixture was vortexed for $90 \mathrm{sec}$. The cell suspensions were incubated for $16 \mathrm{~h}$ in a $30^{\circ} \mathrm{C}$ water bath either with or without $1 \mathrm{mM} L$-dopamine. The suspensions were pelleted in a microcentrifuge at 14,000 $\mathrm{rpm}$ for $30 \mathrm{sec}$, and the supernatants were analyzed in a Beckman DU 640 spectrophotometer at $480 \mathrm{~nm}$. The $A_{480}$ of samples to which $L$-dopamine had been added was compared with the blank sample in which no $L$-dopamine had been added. Data represent geometric means \pm standard deviations of three separate experiments.

\section{Animal model of cryptococcal meningitis}

New Zealand White rabbits weighing 2-3 kg were housed in separate cages and provided with water ad libitum and Purina rabbit chow. Wild-type $\mathrm{H} 99$ and the isogenic GAL7::IPC1 strains were prepared by growth for $48 \mathrm{~h}$ at $30^{\circ}$ in YPD medium. The cells were pelleted, washed twice, and suspended in PBS at a concentration of $5 \times 10^{8}$ cells $/ \mathrm{mL}$. After sedation with ketamine (Fort Dodge) and xylazine (Vedco), $\sim 3 \times 10^{8}$ viable cells of each strain were inoculated intracisternally into three rabbits that had received an intramuscular injection of cortisone acetate at $2.5 \mathrm{mg} / \mathrm{kg}$ (Merck) $1 \mathrm{~d}$ earlier and then daily for $14 \mathrm{~d}$. Three rabbits received the wild-type H99 strain, three rabbits received the GAL7::IPC1 strain (\#10), and three rabbits received a second independent GAL7::IPC1 transformant (\#13). Rabbits were sedated with ketamine and xylazine on days $4,7,11$, and 14 after inoculation, and CSF was withdrawn. Quantitative yeast cultures were performed by diluting the CSF in PBS, plating on YPD medium, and incubating for $72 \mathrm{~h}$ at $30^{\circ} \mathrm{C}$.

\section{Intracellular growth in 7774.16 macrophage-like cell line}

J774.16 is a murine reticulum sarcoma macrophage-like cell line that has been extensively characterized (Chang et al. 1992). The intracellular growth of C. neoformans into J774.16 macrophage-like cells was studied as previously described (Mukherjee et al. 1995; Mukherjee et al. 1996; Cox et al., in prep.). In brief, J774.16 cells were used up to passage \#10, with each passage dilution equal to $1: 15$. Cells were plated on $35 \times 10$-mm plates (Constar Corp.) and maintained in DMEM supplemented with $10 \%$ fetal calf serum and $1 \times$ penicillin/streptomycin at $37^{\circ} \mathrm{C}$ with $10 \% \mathrm{CO}_{2}$. Just before the infection, $2 \mathrm{~mL}$ of the fresh medium containing $2 \%$ glucose or $2 \%$ galactose was added to the cells. Then, 50 units/mL of IFN- $\gamma$ (Genzyme Corp.), 0.3 $\mu \mathrm{g} / \mathrm{mL}$ of LPS (Sigma Chemical Co.), and $10 \mu \mathrm{g} / \mathrm{mL}$ of $18 \mathrm{~B} 7$ (IgG-specific anti-GXM monoclonal antibody) were added to the cells. Finally, C. neoformans wild-type H99 and GAL7::IPC1 (\#10) strains were grown on YPD for $48 \mathrm{~h}$ at $30^{\circ} \mathrm{C}$, washed three times in PBS, and added to the J774.16 cells at a multiplicity of infection (effector to target ratio of 1:1). After a short incubation (30 min to $1 \mathrm{~h}$ ), extracellular C. neoformans cells were washed away with three changes in cell culture media. The imaging of cells was performed with a Photometrics Sensys cooled CCD camera on an Olympus IX 70 microscope. The temperature was kept constant at $37^{\circ} \mathrm{C}$ by both a heated stage and heated air unit supplied by Olympus. The Plexiglas environment surrounding the microscope was kept under positive pressure with $5 \% \mathrm{CO}_{2} /$ $95 \%$ air. Imaging software was IP Lab Spectrum running on a Macintosh G3. At the $5 \mathrm{~h}$ time point buds were counted, and the percentage of budding cells per the phagocytic index was recorded. The phagocytic index is the number of internalized yeast per number of macrophages per field. Data are geometric means \pm standard deviations of four different fields.

\section{Acknowledgments}

We thank Meiquing Shen and Allyson Plowden for technical assistance, Ogretmen Besim for helping in RNA extraction, Lina Obeid, Cungui Mao, Gary M. Jenkins, Yasuo Okamoto, Cletus A. D'Souza, Andrew Alspaugh, and Joseph Heitman for discussion, and LuAnne Harley for helping on the preparation of this manuscript. This work was supported in part by MUCU Institutional Project 21363, in part by grant GM 43825, in part by PO1 grant AI44975 from NIAID to the Duke University Mycology Research Units, in part by NIAID grant AI28388, and in part by grant HL59842.

The publication costs of this article were defrayed in part by payment of page charges. This article must therefore be hereby marked "advertisement" in accordance with 18 USC section 1734 solely to indicate this fact.

\section{References}

Agin, P.P., Dowdy, J.C., and Costlow, M.E. 1991. Diacylglycerol-induced melanogenesis in Skh-2 pigmented hair-less mice. Photodermatol. Photoimmunol. Photomed. 8: 51-56.

Alspaugh, J.A., Perfect, J.R., and Heitman, J. 1997. Cryptococcus neoformans mating and virulence are regulated by the Gprotein $\alpha$ subunit GPA1 and cAMP. Genes \& Dev. 11: 32063217.

Alspaugh, J.A., Perfect, J.R., and Heitman, J. 1998. Signal transduction pathways regulating differentiation and pathogenicity of Cryptococcus neoformans. Fungal Genet. Biol. 25: 114.

Barluzzi, R., Brozzetti, A., Mariucci, G., Tantucci, M., Neglia, R.G., Bistoni, F., and Blasi, E. 2000. Establishment of protective immunity against cerebral cryptococcosis by means of an avirulent, non melanogenic Cryptococcus neoformans strain. J. Neuroimmunol. 109: 75-86.

Bradford, M.M. 1976. A rapid and sensitive method for the quantitation of microgram quantities of protein utilizing the principle of protein-dye binding. Anal. Biochem. 72: 248-254.

Casadevall, A. and Perfect, J.R. 1998. Cryptococcus neoformans. American Society for Microbiology, Washington, DC.

Casadevall, A., Rosas, A.L., and Nosanchuk, J.D. 2000. Melanin and virulence in Cryptococcus neoformans. Curr. Opin. Microbiol. 3: 354-358.

Chang, J., Xing, Y., Magliozzo, R.S., and Bloom, B.R. 1992. Killing of virulent Mycobacterium tuberculosis by reactive nitrogen intermediates produced by activated murine macrophages. J. Exp. Med. 175: 1111-1122.

Chang, Y.C. and Kwon-Chung, K.J. 1994. Complementation of a capsule-deficient mutation of Cryptococcus neoformans restores its virulence. Mol. Cell. Biol. 14: 4912-4919.

Chaturvedi, V., Flynn, T., Niehaus, W.G., and Wong, B. 1996. Stress tolerance and pathogenic potential of a mannitol mutant of Cryptococcus neoformans. Microbiology 142: 937943.

Chung, N., Jenkins, G., Hannun, Y.A., Heitman, J., and Obeid, L.M. 2000. Sphingolipids signal heat stress-induced ubiquitin-dependent proteolysis. J. Biol. Chem. 275: 17229-17232.

Cruz, M.C., Cavallo, L.M., Gorlach, J.M., Cox, G., Perfect, J.R., Cardenas, M.E., and Heitman, J. 1999. Rapamycin antifungal 
action is mediated via conserved complexes with FKBP12 and TOR kinase homologs in Cryptococcus neoformans. Mol. Cell. Biol. 19: 4101-4112.

De Oliviera, A.R., Castrucci, A.M., and Visconti, M.A. 1996. Cellular signalling in vertebrate pigment cells. Braz. J. Med. Biol. Res. 29: 1743-1749.

Del Poeta, M., Toffaletti, D.L., Rude, T.H., Dykstra, C.C., Heitman, J., and Perfect, J.R. 1999a. Topoisomerase I is essential in Cryptococcus neoformans: Role in pathobiology and as an antifungal target. Genetics 152: 167-178.

Del Poeta, M., Toffaletti, D.L., Rude, T.H., Sparks, S.D., Heitman, J., and Perfect, J.R. 1999b. Cryptococcus neoformans differential gene expression detected in vitro and in vivo with green fluorescent protein. Infect. Immun. 67: 1812-1820.

Diamond, R.D. and Bennett, J.E. 1973. Disseminated cryptococcosis in man: Decreased lymphocyte transformation in response to Cryptococcus neoformans. J. Infect. Dis. 127: 694697.

Dickson, R.C. and Lester, R.L. 1999. Yeast sphingolipids. Biochim. Biophys. Acta 1426: 347-357.

Doering, T.L., Nosanchuk, J.D., Roberts, W.K., and Casadevall, A. 1999. Melanin as a potential cryptococcal defence against microbicidal proteins. Med. Mycol. 37: 175-181.

Feldmesser, M., Kress, Y., Novikoff, P., and Casadevall, A. 2000. Cryptococcus neoformans is a facultative intracellular pathogen in murine pulmonary infection. Infect. Immunol. 68: 4225-4237.

Fischl, A.S., Liu, Y., Browdy, A., and Cremesti, A.E. 2000. Inositolphosphoryl ceramide synthase from yeast. Meth. Enzymol. 311: 123-130.

Fostel, J.M. and Lartey, P.A. 2000. Emerging novel antifungal agents. Drug Discov. Today 5: 25-32.

Franzot, S.P., Mukherjee, J., Cherniak, R., Chen, L.C., Hamdan, J.S., and Casadevall, A. 1998. Microevolution of a standard strain of Cryptococcus neoformans resulting in differences in virulence and other phenotypes. Infect. Immunol. 66: 8997.

Fries, B.C., Goldman, D.L., Cherniak, R., Ju, R., and Casadevall, A. 1999. Phenotypic switching in Cryptococcus neoformans results in changes in cellular morphology and glucuronoxylomannan structure. Infect. Immunol. 67: 6076-6083.

Gilchrest, B.A., Park, H.Y., Eller, M.S., and Yaar, M. 1996. Mechanisms of ultraviolet light-induced pigmentation. Photochem. Photobiol. 63: 1-10.

Hannun, Y.A. and Luberto, C. 2000. Ceramide in the eukaryotic stress response. Trends Cell. Biol. 10: 73-80.

Hashida-Okado, T., Ogawa, A., Endo, M., Yasumoto, R., Takesako, K., and Kato, I. 1996. AUR1, a novel gene conferring aureobasidin resistance on Saccharomyces cerevisiae: A study of defective morphologies in Aurlp-depleted cells. Mol. Gen. Genet. 251: 236-244.

Heidler, S.A. and Radding, J.A. 1995. The AUR1 gene in Saccharomyces cerevisiae encodes dominant resistance to the antifungal agent aureobasidin A (LY295337). Antimicrob. Agents Chemother. 39: 2765-2769.

- 2000. Inositol phosphoryl transferases from human pathogenic fungi. Biochim. Biophys. Acta 1500: 147-152.

Howard, D.H. 1961. Some factors which affect the initiation of growth of Cryptococcus neoformans. J. Bacteriol. 82: 430435.

Huffnagle, G.B. and McNeil, L.K. 1999. Dissemination of C. neoformans to the central nervous system: Role of chemokines, Th1 immunity and leukocyte recruitment. J. Neurovirol. 5: 76-81.

Jenkins, G.M., Richards, A., Wahl, T., Mao, C., Obeid, L., and
Hannun, Y. 1997. Involvement of yeast sphingolipids in the heat stress response of Saccharomyces cerevisiae. I. Biol. Chem. 272: 32566-32572.

Kuroda, M., Hashida-Okado, T., Yasumoto, R., Gomi, K., Kato, I., and Takesako, K. 1999. An aureobasidin A resistance gene isolated from Aspergillus is a homolog of yeast $A U R 1$, a gene responsible for inositol phosphorylceramide (IPC) synthase activity. Mol. Gen. Genet. 261: 290-296.

Kwon-Chung, K.J. and Popkin, T.J. 1976. Ultrastructure of septal complex in Filobasidiella neoformans (Cryptococcus neoformans). J. Bacteriol. 126: 524-528.

Kwon-Chung, K.J., Polacheck, I., and Popkin, T.J. 1982. Melanin-lacking mutants of Cryptococcus neoformans and their virulence for mice. J. Bacteriol. 150: 1414-1421.

Lester, R.L., Wells, G.B., Oxford, G., and Dickson, R.C. 1993. Mutant strains of Saccharomyces cerevisiae lacking sphingolipids synthesize novel inositol glycerophospholipids that mimic sphingolipid structures. J. Biol. Chem. 268: 845-856.

Levine, T.P., Wiggins, C.A.R., and Munro, S. 2000. Inositol phosphorylceramide synthase is located in the Golgi apparatus of Saccharomyces cerevisiae. Mol. Biol. Cell 11: 22672281.

Levitz, S.M. and Tabuni, A. 1991. Binding of Cryptococcus neoformans by human cultured macrophages. Requirements for multiple complement receptors and actin. J. Clin. Invest. 87: 528-535.

Levitz, S.M., Harrison, T.S., Tabuni, A., and Liu, X. 1997. Chloroquine induces human mononuclear phagocytes to inhibit and kill Cryptococcus neoformans by a mechanism independent of iron deprivation. J. Clin. Invest. 100: 1640-1646.

Levitz, S.M., Nong, S.-H., Seeto, K.F., Harrison, T.S., Speizer, R.A., and Simons, E.R. 1999. Cryptococcus neoformans resides in an acidic phagolysosome of human macrophages. Infect. Immunol. 67: 885-890.

Liu, L., Tewari, R.P., and Williamson, P.R. 1999. Laccase protects Cryptococcus neoformans from antifungal activity of alveolar macrophages. Infect. Immunol. 67: 6034-6039.

Lodge, J.K., Jackson-Machelski, E., Toffaletti, D.L., Perfect, J.R., and Gordon, J.I. 1994. Targeted gene replacement demonstrates that myristoyl-CoA: Protein N-myristoyltransferase is essential for viability of Cryptococcus neoformans. Proc. Natl. Acad. Sci. 91: 12008-12012.

Mandala, S.M., Thornton, R.A., Milligan, J., Rosenbach, M., Garcia-Calvo, M., Bull, H.G., Harris, G., Abruzzo, G.K., Flattery, A.M., Gill, C.J., et al. 1998. Rustmicin, a potent antifungal agent, inhibits sphingolipid synthesis at inositol phosphoceramide synthase. I. Biol. Chem. 273: 1494214949.

Moore, T.D. and Edman, J.C. 1993. The alpha-mating type locus of Cryptococcus neoformans contains a peptide pheromone gene. Mol. Cell. Biol. 13: 1962-1970.

Mukherjee, S., Lee, S.C., and Casadevall, A. 1995. Antibodies to Cryptococcus neoformans glucuronoxylomannan enhance antifungal activity of murine macrophages. Infect. Immunol. 63: $573-579$.

Mukherjee, S., Feldmesser, M., and Casadevall, A. 1996. J774 murine macrophage-like cell interactions with Cryptococcus neoformans in the presence and absence of opsonins. I. Infect. Dis. 173: 1222-1231.

Nagiec, R.M., Wells, G.B., Lester, R.L., and Dickson, R.C. 1993. A suppressor gene enables Saccharomyces cerevisiae to grow without making sphingolipids encodes a protein that resembles an Escherichia coli fatty acyltransferase. J. Biol. Chem. 268: 22156-22163.

Nosanchuk, J.D., Rosas, A.L., and Casadevall, A. 1998. The antibody response to fungal melanin in mice. I. Immunol. 
Luberto et al.

160: 6026-6031.

Nosanchuk, J.D., Valadon, P., Feldmesser, M., and Casadevall, A. 1999. Melanization of Cryptococcus neoformans in murine infection. Mol. Cell. Biol. 19: 745-750.

Odom, A., Muir, S., Lim, E., Toffaletti, D.L., Perfect, J., and Heitman, J. 1997. Calcineurin is required for virulence of Cryptococcus neoformans. EMBO J. 16: 2576-2589.

Perfect, J.R., Lang, S.D., and Durack, D.T. 1980. Chronic cryptococcal meningitis: A new experimental model in rabbits. Am. J. Pathol. 101: 177-194.

Perfect, J.R., Toffaletti, D.L., and Rude, T.H. 1993. The gene encoding phosphoribosylaminoimidazole carboxylase (ADE2) is essential for growth of Cryptococcus neoformans in cerebrospinal fluid. Infect. Immunol. 61: 4446-4451.

Perfect, J.R., Wong, B., Chang, Y.C., Kwon-Chung, K.J., and Williamson, P.R. 1998. Cryptococcus neoformans: Virulence and host defences. Med. Mycol. 36: 79-86.

Polacheck, I. and Kwon-Chung, K.J. 1988. Melanogenesis in Cryptococcus neoformans. J. Gen. Microbiol. 134: 10371041.

Polacheck, I., Platt, Y., and Aronovitch, J. 1990. Catecholamines and virulence of Cryptococcus neoformans. Infect. Immunol. 58: 2919-2922.

Rhodes, J.C., Polacheck, I., and Kwon-Chung, K.J. 1982. Phenoloxidase activity and virulence in isogenic strains of Cryptococcus neoformans. Infect. Immunol. 36: 1175-1184.

Salas, S.D., Bennett, J.E., Kwon-Chung, K.J., Perfect, J.R., and Williamson, P.R. 1996. Effect of the laccase gene CNLAC1, on virulence of Cryptococcus neoformans. I. Exp. Med. 184: 377-386.

Sambrook, J., Fritsch, E.F., and Maniatis, T. 1989. Molecular cloning: A laboratory manual, 2nd ed. Cold Spring Harbor Laboratory Press, Cold Spring Harbor, NY.

Schnitzler, N., Peltroche-Llacsahuanga, H., Bestier, N., Zundorf, J., Lutticken, R., and Haase, G. 1999. Effect of melanin and carotenoids of Exophiala (Wangiella) dermatitidis on phagocytosis, oxidative burst, and killing by human neutrophilis. Infect. Immunol. 67: 94-101.

Toffaletti, D.L., Rude, T.H., Johnston, S.A., Durack, D.T., and Perfect, J.R. 1993. Gene transfer in Cryptococcus neoformans by use of biolistic delivery of DNA. J. Bacteriol. 175: 1405-1411.

Wang, P. and Heitman, J. 1999. Signal transduction cascades regulating mating, filamentation, and virulence in Cryptococcus neoformans. Curr. Opin. Microbiol. 2: 358-362.

Wang, Y., Aisen, P., and Casadevall, A. 1995. Cryptococcus neoformans melanin and virulence: Mechanism of action. Infect. Immunol. 63: 3131-3136.

Wickes, B.L. and Edman, J.C. 1995. The Cryptococcus neoformans GAL7 gene and its use as an inducible promoter. Mol. Microbiol. 16: 1099-1109.

Williamson, P.R., Wakamatsu, K., and Ito, S. 1998. Melanin biosynthesis in Cryptococcus neoformans. I. Bacteriol. 180: $1570-1572$.

Wills, E.A., Rebindo, M.R., Perfect, J.R., and Del Poeta, M. 2000. New potential targets for antifungal development. Emerg. Ther. Targets 4: 265-296.

Yue, C., Cavallo, L.M., Alspaugh, J.A., Wang, P., Cox, G.M., Perfect, J.R., and Heitman, J. 1999. The STE12 $\alpha$ homolog is required for aploid filamentation but largely dispensable for mating and virulence in Cryptococcus neoformans. Genetics 153: 1601-1615. 


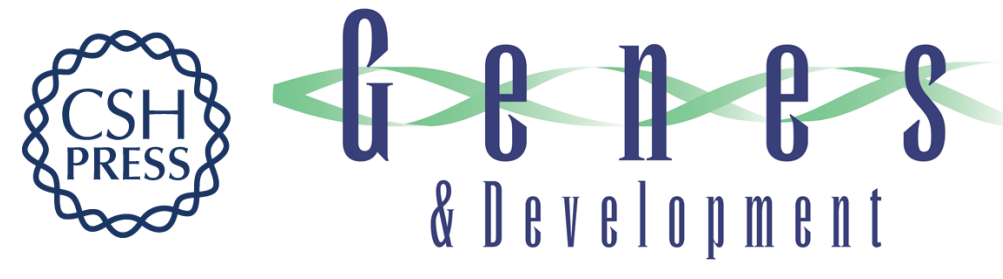

\section{Roles for inositol-phosphoryl ceramide synthase 1 (IPC1) in pathogenesis of C. neoformans}

Chiara Luberto, Dena L. Toffaletti, Elizabeth A. Wills, et al.

Genes Dev. 2001, 15:

Access the most recent version at doi:10.1101/gad.856001

References This article cites 61 articles, 36 of which can be accessed free at: http://genesdev.cshlp.org/content/15/2/201.full.htmI\#ref-list-1

License

Email Alerting

Receive free email alerts when new articles cite this article - sign up in the box at the top Service right corner of the article or click here.

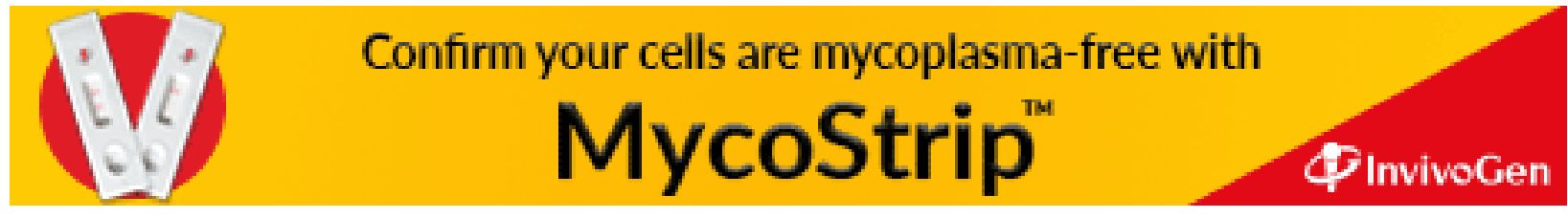

